\section{Earthquake near Kamchatka}

ON November 4 at 16h. 58m. 20s. G.M.T., an earthquake occurred with epicentre, according to calculations made at the U.S. Coast and Geodetic Survey in Washington, at lat. $52 \frac{1}{2}^{\circ} \mathrm{N}$., long. $159^{\circ}$ E., near the east coast of Kamchatka. It was recorded strongly at seismological observatories throughout the world and had a magnitude of $8 \frac{1}{3}$ on the Gutenberg-Richter logarithmic scale. This is a smaller magnitude than that of the great Sikang-Assam earthquake of August 15, 1950 ; but had the Kamchatka earthquake happened on land it would undoubtedly have occasioned great damage. Faulting probably took place in the sea bed near the epicentre, since a great tsunami or seismic sea wave resulted, and spread throughout the Pacific Ocean. It arrived at the coast of northern Japan about 20h. G.M.T. on November 4. The Hawaiian warning system was used, and the coastlands of several islands, including the Oahu coast, were evacuated in anticipation of the wave. When the wave arrived at Hawaii itself, it is reported to have been several feet high, and would have caused much damage had not precautions been taken. Waves from one to three feet high arrived at the Whangarei beaches in the north of New Zealand about 7 p.m. local time on November 5. When these waves arrived at Wellington, they were 6-8 in. high. No news has yet been received from the nearest town to the epicentre-Petropavlovsk on the Kamchatka Peninsula-nor from the International Seismological Association central station at Strasbourg. Immediately following the main shock, there were more than a hundred aftershocks. Further news is awaited.

Provisional readings, all in G.M.T., of seismograms at Pasadena were: $e P, 17 \mathrm{~h}$. 08m. 23s.; $i P, 17 \mathrm{~h}$. $08 \mathrm{~m} .37 \mathrm{~s} . ; e(P P), 17 \mathrm{~h} .11 \mathrm{~m} .0 \mathrm{~s} . ; e S, 17 \mathrm{~h} .16 \mathrm{~m} .39 \mathrm{~s} . ;$ $i S, 17 \mathrm{~h} .16 \mathrm{~m} .48 \mathrm{~s} . ; i(S c S)$, 17h. 18m. 11s.; $e G, 17 \mathrm{~h}$. $23 \cdot 2 \mathrm{~m}$. ; $i G 2,19 \mathrm{~h}$. 22m. ; $\max . H, 2,000 \pm \mu$; and at Stuttgart: $i P, 17 \mathrm{~h} .10 \mathrm{~m} .12 \cdot 0 \mathrm{~s}$. compression $i, 17 \mathrm{~h}$. 10m. 14.6s. compression; $i !, 17 \mathrm{~h} .10 \mathrm{~m}$. $21 \cdot 0 \mathrm{~s}$. compression; $i$ ! $(P c P), 17 \mathrm{~h} .10 \mathrm{~m} .24 \cdot 0 \mathrm{~s}$. dilatation; $i P P, 17 \mathrm{~h} .13 \mathrm{~m} .20 \mathrm{~s} . ; i S, 17 \mathrm{~h} .20 \mathrm{~m} .10 \mathrm{~s}$.; $e G, 17 \mathrm{~h} .3 \mathrm{~lm} .(T=80$ sec. !) ; $M Q$, 17h. $40 \mathrm{~m}$. ; $M R$, 17h. $41-42 \mathrm{~m} .(Z=5,400 \mu) ; M R, 17 \mathrm{~h} .50 \mathrm{~m}$.

\section{The Night Sky in December}

Fuls moon occurs on Dec. 1d. 12h. 4lm., U.T., and new moon on Dec. 17d. 02h. $02 \mathrm{~m}$. The following conjunctions with the moon take place: Dec. 12d. 20h., Saturn $8^{\circ}$ N. ; Dec. 15d. 14h., Mereury $7^{\circ}$ N. ; Dec. 20d. 08h., Venus $2^{\circ}$ S. ; Dec. 2ld. 02h., Mars $2^{\circ}$ S. ; Dec. 26d. 20h., Jupiter $7^{\circ}$ S. Mereury is too close to the sun at the beginning of December for favourable observation, but at the middle and end of the month its times of rising are $6 \mathrm{~h} .05 \mathrm{~m}$. and $6 \mathrm{~h}$. $50 \mathrm{~m}$., respectively, and it can be seen for a short time before sunrise; owing to its large southern declination, it will not rise far above the horizon. Venus is an evening star, setting at $18 \mathrm{~h} .25 \mathrm{~m} ., 19 \mathrm{~h}$. $05 \mathrm{~m}$. and $19 \mathrm{~h}$. $50 \mathrm{~m}$. on December 1,15 and 31 , respectively. The visible portion of the illuminated disk varies from 0.75 to 0.65 , and the stellar magnitude averages $-3 \cdot 7$. Mars, an evening star, sets at about $20 \mathrm{~h} .20 \mathrm{~m}$. throughout the month, stellar magnitude about $1 \cdot 1$. It is easily recognized during the middle of December close to $\gamma$ and $\delta$ Capricorni. Jupiter is visible throughout the night, setting in the morning hours at $5 \mathrm{~h} .15 \mathrm{~m} ., 4 \mathrm{~h} .15 \mathrm{~m}$. and $3 \mathrm{~h} .10 \mathrm{~m}$. on December 1, 15 and 31 respectively, stellar magnitude about $-2 \cdot 3$. Saturn, a morning star, rises at $3 \mathrm{~h} .25 \mathrm{~m} ., 2 \mathrm{~h} .40 \mathrm{~m}$. and $1 \mathrm{~h} .40 \mathrm{~m}$. at the beginning, middle and end of the month, respectively, stellar magnitude $0 \cdot 9$, and is visible for some hours before sunrise in the constellation of Virgo. Occultations of stars brighter than magnitude 6 are as follows, observations being made at Greenwich : Dec. $4 \mathrm{~d}$. 1h. 55m., 37 Gemi. $(R)$; Dec. 6d. 5h. 11.7m., \& Canc. $(D)$; Dec. 6d. 6h. 15.9m., $\delta$ Canc. $(R)$; Dec. $28 \mathrm{~d}$. 1h. $24 \cdot 3 \mathrm{~m} ., 16$ Taur. $(D)$; Dec. 28d. 1h. 31.4m., $q$ Taur. $(D)$; Dec. 28d. 1h. 50.7m., 20 Taur. $(D)$; Dec. 28 d. 1h. $53 \cdot 7 \mathrm{~m} ., 21$ Taur. $(D) . R$ and $D$ refer to reappearance and disappearance, respectively. Winter solstice takes place on Dec. 21d. 22h. Observation of the Geminid meteors during the first week in December will be difficult owing to moonlight.

\section{Announcements}

THE conference this year of the Universities of Great Britain and Northern Ireland, convened by the Committee of Vice-Chancellors and Principals, will be held in the Senate House of the University of London during December 12-13. There will be three sessions on the following subjects : halls of residence and student amenities; success and failure at the university; and vacation employment. 'The Conference is only open to delegations appointed by the universities and to specially invited guests. Further details can be obtained from the secretary of the Committee, J. F. Foster, at 5 Gordon Square, London, W.C.1.

ON the occasion of the twenty-second annual general meeting of the Printing, Packaging and Allied Trades Research Association, an exhibition of the Association's work will be held at the Connaught Rooms, Great Queen Street, London, W.C.2, on December 4. The displays will illustrate the work carried out in the Association's laboratories on the chemistry and physics of printing inks, papers, the testing of packages and containers, bookbinding, and the protection of packages against insect attack. New apparatus and new wash-up solvents will be shown, and the manner in which the Association endeavours to place its findings before its members will be illustrated. Further details can be obtained from the Association at Patra House, Randalls Road, Leatherhead, Surrey.

THE National Science Foundation and the University of Rochester are sponsoring a conference on highenergy nuclear physics to be held in Rochester, N.Y., during December 18-20. The conference will be financed by a 2,000-dollar grant from the Foundation and contributions from several industrial firms in Rochester. The conference will bring together about seventy nuclear physicists from the United States, Canada and Mexico to discuss recent research findings on high-energy particles and to plan future studies in this field. Further information can be obtained from the National Science Foundation, 2144 California Street, N.W., Washington 25, D.C., or from the Department of Physics, University, Rochester, N.Y.

In the April and May issues of L'Astronomie there are two accounts of the eclipse of the sun at Khartoum on February 25, with a number of photographs taken by J. Leclerc and E. Geneslay. The first account is by several authors, and the second by L. D'Azambuja, of the Paris-Meudon Observatory. These detailed descriptions will prove very helpful to everyone interested in solar eclipses. 